Mehmet Akif Ersoy Üniversitesi Fen Bilimleri Enstitüsü Dergisi 11(2): 164-175 (2020)

The Journal of Graduate School of Natural and Applied Sciences of Mehmet Akif Ersoy University 11(2): 164-175 (2020)

Araştırma Makalesi / Research Paper

\title{
Karbon Fiber Takviyeli Kompozit Malzemenin Kuru ve Kriyojenik Şartlarda Delinebilirliğinin Deneysel Araştırılması
}

\author{
Gültekin BASMACI ${ }^{(1 *}{ }^{*}$, Ahmet Said YÖRÜK ${ }^{\mathbb{D}} 2$ \\ ${ }^{1}$ Burdur Mehmet Akif Ersoy Üniversitesi, Mühendislik-Mimarlık Fakültesi, Burdur \\ ${ }^{2}$ Iğdır Üniversitesi, Teknik Bilimler Meslek Yüksekokulu, Iğdır \\ Geliş Tarihi (Received): 31.05.2020, Kabul Tarihi (Accepted): 25.07.2020 \\ $\square$ Sorumlu Yazar (Corresponding author*): gbasmaci@mehmetakif.edu.tr \\ (C) +902482132715 且 +902482132704
}

öz

Bu çalışmada, Karbon Fiber Takviyeli Kompozit Malzemelerin (CFRP) kuru ve kriyojenik şartlar altında farklı kesme parametreleri ve farklı çaplı matkaplarla delinmesi, delaminasyon hasarı, delik çapı ve yüzey kalitesine etkisi deneysel olarak incelenmiştir. Deneysel çalışmada iki farklı kesme hızı (20 ve $50 \mathrm{~m} /$ dak.), dört farklı ilerleme miktarı $(0.075 \mathrm{~mm} / \mathrm{dev}$., $0.15 \mathrm{~mm} / \mathrm{dev}$., $0.225 \mathrm{~mm} / \mathrm{dev}$. ve $0.3 \mathrm{~mm} / \mathrm{dev})$ ve 2 farklı çaplı matkaplar $(4 \mathrm{~mm}$ ve $6 \mathrm{~mm})$ kuru ve kriyojenik şartlar altında yapılan deneysel tasarımın değerleri uygulanmıştır. Sonuçlar, daldırma kriyojenik tekniği ile CFRP'nin delinmesinin kolaylaştığı, delinmiş parçaların yüzey pürüzlülüğünü azaltarak işlenebilirliği büyük ölçüde artırdığını göstermiştir. Bununla birlikte, itme kuvveti ve delaminasyon faktörü artmıştır.

Anahtar Kelimeler: CFRP, delaminasyon, delik delme, kriyojenik

\section{Experimental Study on the Dirilling of the Carbon Fiber Reinforced Polymer Composites under Dry and Criyogenic Conditions}

\begin{abstract}
In this study, the effect of drilling Carbon Fiber Reinforced Products (CFRP) under dry and cryogenic conditions with different diametered drill bits and different cutting parameters on delamination injury, hole diameter and on surface quality were investigated experimentally. Two different cutting speed (20 and $50 \mathrm{~m} / \mathrm{min}$ ), four different moving amount $(0.075 \mathrm{~mm} / \mathrm{rev}, 0.15 \mathrm{~mm} / \mathrm{rev}, 0.225 \mathrm{~mm} / \mathrm{rev}$ and $0.3 \mathrm{~mm} / \mathrm{rev}$ ) and two different diametered drill $(4 \mathrm{~mm}$ and $6 \mathrm{~mm})$ values for experimental design have been applied under dry and cryogenic conditions in this study. The results showed that the penetration of CFRP by the immersion cryogenic technique was facilitated, greatly improving the machinability by reducing the surface roughness of the drilled parts. However, thrust and delamination factor increased.
\end{abstract}

Keywords: CFRP, delamination, drilling, cryogenic

\section{GiRiş}

Bilimsel gelişmeler, mühendislik alanındaki problemlere farklı bir yaklaşım getirmiştir. Bilinen malzeme ve üretim yöntemlerin, yerini yeni materyallere, üretim ve imalat şekillerine bırakmışlardır. Materyal seçimleri, materyallerin çalışma şekline göre yenilendiği gibi imalat şekilleri de bu materyallerin üretimine uygun olarak tasarlanmıştır. Bunun için kompozit malzemelerin, diğer malzemelerden yüksek olan yönleri dolaysıyla pek çok sanayi alanında daha önceki malzemelerin yerine geçmiştir. İmalat yöntemleri yeniden tasarlanmış, önceki imalat yöntemleri ile farklılıklar gözlemlenerek bu malzemelerin özel- 
liklerinin daha ileriye götürmek için araştırmalar yapılmaya başlanmıştır. Liyakhath ve ark. (2015) çalışmalarında farklı imalat yöntemlerinin geliştirildiği ve farklı imalat metotlarının belirlendiği bu süreçte ve yakın bir zaman diliminde daha da ilerleyeceği görülmektedir.

Farklı yapıya sahip birden çok malzemenin, aralarında farklılık gösteren bir ara yüzey bulunan ve bu malzemelerin mikroskobik birlikteliği neticesinde, bir araya getirilen malzemelerin gösteremediği veya daha iyi fiziksel özellikleri elde etmek için kompozit malzemeler imal edilir. Kompozit malzemelerin mühendislik uygulamalarında tercih edilme sebebi diğer malzemelere göre daha yüksek rijitlik, mukavemet ve yüksek sıcaklık performansı, korozyon direnci, sertlik ve iletkenlik ve daha hafif olmaları gibi etkenlerdir. Ananda ve ark. (2009) çalışmalarında kompozit malzeme genel olarak, kendisini oluşturan malzemelerin tek başlarına gösterdikleri fiziksel özelliklerden daha iyi neticeler belirtmişlerdir. Kesme kenarının önündeki ilk fiber ayrılmasından dolayı komponentleri zorlamaya ek olarak, CFRP malzemesinin kanat yüzü üzerindeki elastik yay geri etkileri nedeniyle ilave kuvvet bileşenleri dikkate alınır. Delme kinematiği ile birleştiğinde ve eğik kesme koşulları göz önüne alındığında, itme kuvveti ve tork değerleri, yarım takım dönüşü sırasında tüm fiber kesme açıları aralığı için analitik olarak belirlemişlerdir (Sheeholzer ve ark., 2020).

Karbon fiber takviyeli polimer matrisli kompozitler (CFRP), yüksek dayanım ve mukavemet kapasitesinin yanında düşük yoğunlukları sebebiyle, özellikle son yıllarda, hafif yapılar da ve imalat alanında kullanılmaktadır. Yüksek performanslı kompozitlerde termosetlerin kullanılmasıyla birlikte, termoplastikler de düşük su geçirgenliği, yüksek sıcaklıklarda kimyasal direnç, yüksek tokluk, şekillendirilebilme kabiliyeti, boyutsal kararlılık, geri dönüşüm, toksik ve korozif olmama gibi çeşitli fiziksel özelliklerinden dolayı tercih edilmektedir (Ekici ve Işık, 2009).

Delik delme işlemi, diğer talaşlı imalat yöntemleri içinde ki oranı kayda değer yüksekliktedir. Talaşı imalatta ekseriyetle delik delme işlemi esnasında karşılaşılan sorunların halledilmesine yönelik olarak yapılacak hamleler büyük önem arz etmektedir. Talaşlı imalat işlemlerinde, son yapılan kesme işlemlerinde yüzey kalitesini etkileyen kesme değerleri bulunmaktadır. Bunlar; Kesme hızı, kesme derinliği ve ilerleme hızı değerleri kontrol edilebilen parametrelerdir. Fakat takım geometrisi, takım aşınması, talaş yükleri ve talaş oluşumu veya takım, iş parçası malzeme özellikleri gibi değerler kontrol altına alınamamaktadır. (Meral ve ark., 2011). Karbon fiber takviyeli plastikler (CFRP) hafiflik, yüksek, mukavemet ve sertlik gerektiren havacılık ve otomobil mekanik parçalarına yaygın olarak uygulanır. Havacılık ve otomobil endüstrisinde yerini almıştır (Palanikumar ve ark., 2016).

CFRP yüksek korozyon dayanımı ve hafifliğin yanısıra düşük ısıl genleşme katsayısı gibi önemli özellikleri sahiplenmektedir. Bunun neticesinde modern havacılık ve uzay sektöründe CFRP kullanımı her geçen gün daha da artmaktadır (Gaitonde ve ark., 2008). CFRP malzemeler montaj sırasında en çok delik delme işlemine maruz kalmaktadır. Delme işlemi sırasında delik kalitesi ve bütünlüğü olarak da farklılık göstermektedir (Shunmugesh ve Panneerselvam, 2016). Delaminasyon oluşum mekanizması, delaminasyon niceleme metodolojileri ve ölçüm teknolojileri, delaminasyon bastırma stratejileri (takım tasarımı optimizasyonu dahil), delme koşulları optimizasyonu ve yüksek performanslı delme yöntemlerini kapsamaktadır (Geng ve ark., 2019).

Karbon fiber takviyeli kompozitlerin delik delinmesi esnasında, delaminasyon (delik yüzey hasarı) ve fiber çekilme sorunları ile karşılaşılır. Artan taleple birlikte gelişmiş kompozit malzemeler için farklı kesme koşulları gerekmektedir. Delik delinirken en yaygın kusur delaminasyondur. Delaminasyon, kompozit malzemenin yapısındaki lifler ve matris arasındaki heterojenlik yüzünden meydana geldiğini ifade etmişlerdir (Brinksmeier ve ark., 2011). Karbon fiber takviyeli polimerlerin (CFRP'ler) delme işleminde oluşan çapaklar, delaminasyona neden olabilir, bu nedenle işlem sırasında bileşenlerin taşıma kapasitesini önemli ölçüde azalttığını göstermiştir (Wang ve ark., 2020).

Çalışmamızda, karbon fiber takviyeli kompozit malzemelerin kuru ve kriyojenik şartlar altında farklı kesme parametreleri ile delinmesinde matkap çapının itme kuvveti, delaminasyon hasarı ve delik çapı etkisi deneysel olarak araştırılmıştır. Kriyojenik koşulda işlemede deneylere başlanmadan sıvı nitrojenin kalıbın üzerindeki boşluktan CFRP malzemenin üzerine yüksekliği parçanın kalınlığını $5 \mathrm{~mm}$ geçecek şekilde dökülmesi ve CFRP plakanın soğutulması sağlanmıştır. Bu şekilde uygulanmasındaki sebep sıvı nitrojenin hızla buharlaşmasının önüne geçmektir. Basınçsız sıvı nitrojen tankı Şekil 1 'de gösterilmiştir. 


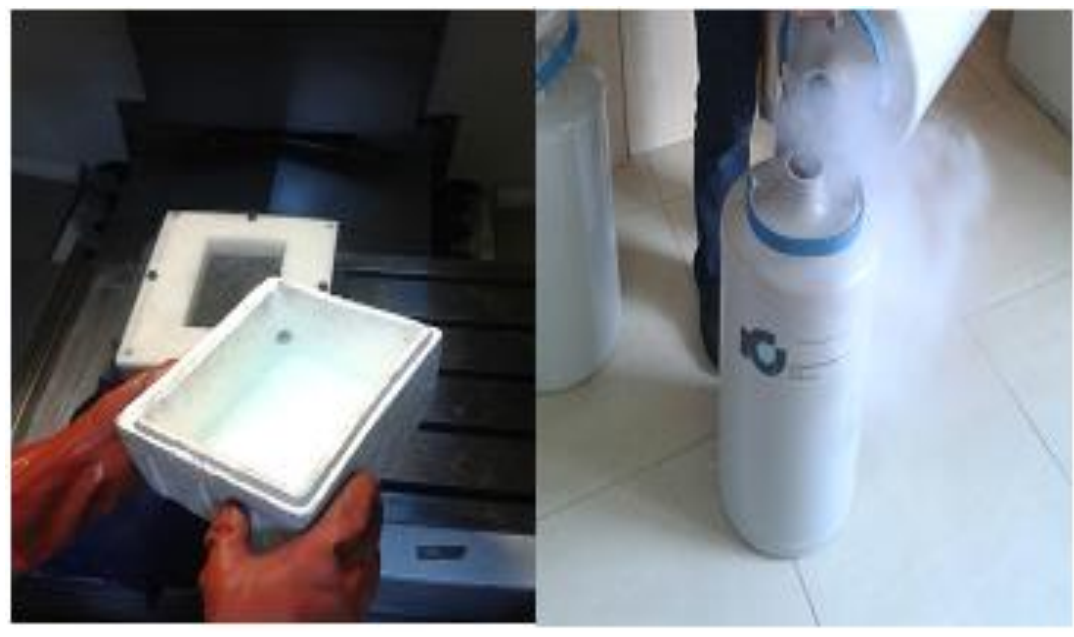

Şekil 1. Sıvı nitrojen muhafaza kabı ve deney kalıbına dökülmesi

\section{MATERYAL VE YÖNTEM}

\section{İşleme Koşulları ve Kesme Parametreleri}

Deneysel çalışmada iki farklı kesme hızı, dört farklı ilerleme miktarı, iki farklı çapa sahip matkap ile kuru ve kriyojenik şartlar altında yapılan deneysel tasarımın değerleri Tablo 1'de verilmiştir. Bu kesme parametreleri kesici takım firma önerileri ve detaylı literatür taramalarından elde edilmiştir.
Deneysel çalışma 3 eksen,10 000 dev/dak. fener mili hızına sahip $17.5 \mathrm{kw}$ gücünde olan Quaser MV154C dik işlem merkezinde gerçekleştirilmiştir. Kesme kuvvetleri ölçümü talaşıı imalatta malzemenin işlenebilirlik değerlendirmesinde önemli bir cihaz Kist'lerdir. Deney anında itme kuvvetleri 9257 B tipi kistler kuvvet ölçüm dinamometresi ve yardımcı ekipmanları (Kistler 5070A amplifikatör, Kistler 5697A veri toplama sistemi (DAQ kartı) ve DynoWare yazılımı) ile yapılmıştır. Kuvvet ölçüm sistemi ve deney düzeneği Şekil 2.' de verilmiştir. Ayrıca Tablo 1 'de kesme şartları gösterilmiştir.

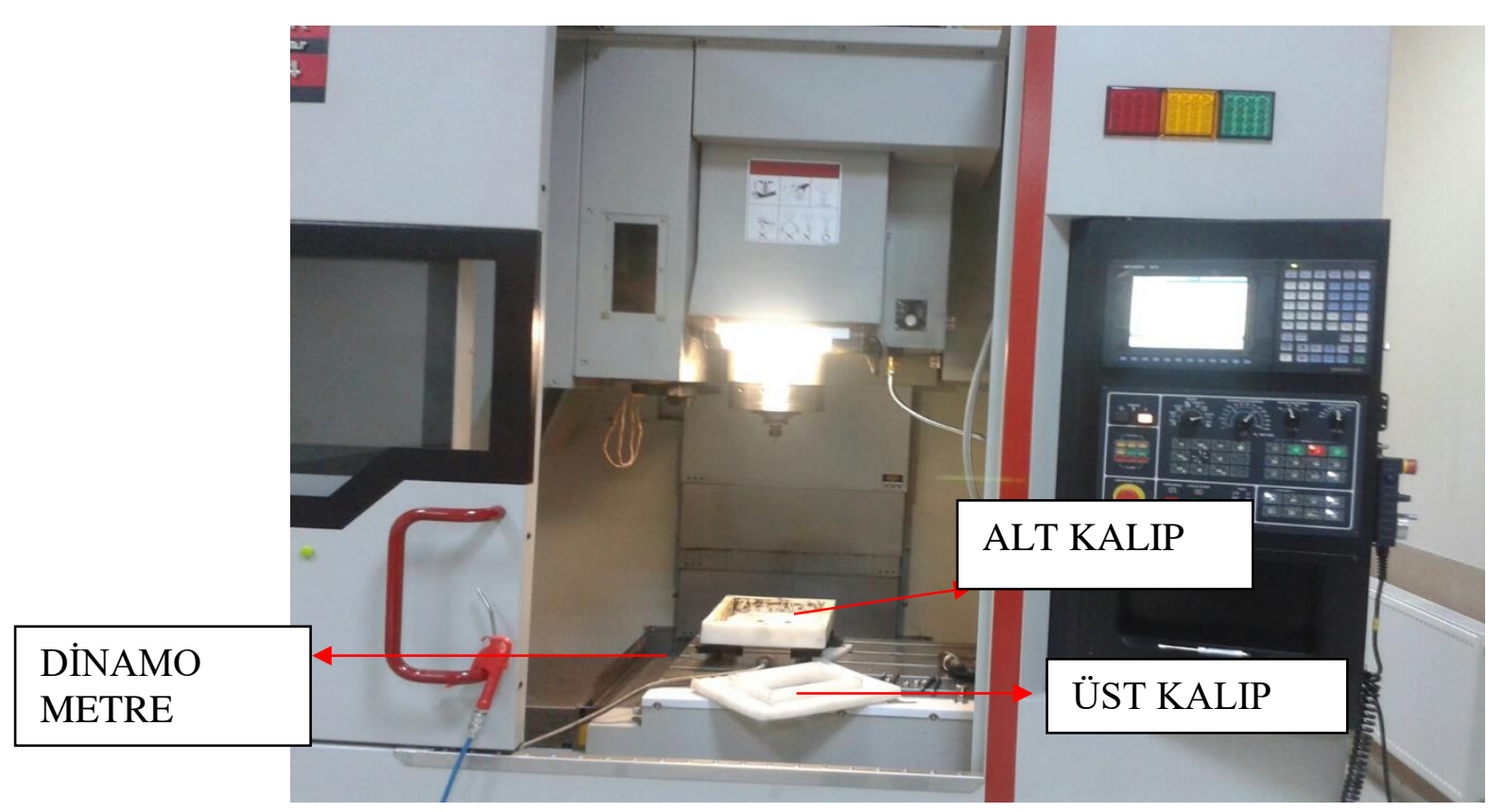

Şekil 2. Kuvvet ölçüm sistemi ve deney düzeneği

Deneylerde kuvvet ölçüm dinamometresi işleme merkezi tablasına paralel ve rijit bir şekilde monte edilmiştir.
Daha sonra dinamometre üzerine kriyojenik şartlar altında işleme yapabilmek için özel olarak imal edilen bağ- 
lama kalıbı bağlanmıştır. Bağlama kalıbı içerisine yalıtkan kalıp monte edilmiştir. Yalıtkan kalıp içerisine kompozit plaka yerleştirilmiştir. Üst kalıp parçası dinamometre üzerindeki bağlama kalıbına bağlanarak numune deneye hazır hale gelmiştir.

\section{Kesici Takım ve Kompozit Malzeme}

Delik delme deneylerinde 4 ve $6 \mathrm{~mm}$ çaplı matkaplar kullanılmıştır. Deneylerde Guhring firmasının G1149 seri numaralı kompozit malzemeleri delmek için geliştirilen matkaplar tercih edilmiştir. Her bir deneyde yeni matkap kullanılmıştır. Deneylerde kullanılan matkapların görüntüsü Şekil 3'de verilmiştir.

Tablo 1. Kesme şartları

\begin{tabular}{|c|c|c|c|c|}
\hline $\begin{array}{l}\text { Deney } \\
\text { Sayısı }\end{array}$ & & Çap $(\varnothing)$ & $\begin{array}{c}\text { Kesme } \\
\text { Hızı } \\
\text { (m/dak) }\end{array}$ & $\begin{array}{c}\text { İlerleme } \\
\text { Miktarı } \\
\text { (mm/dev) }\end{array}$ \\
\hline 1 & \multirow{16}{*}{ 롤 } & \multirow{8}{*}{$4 \mathrm{~mm}$} & \multirow{4}{*}{$20 \mathrm{~m} / \mathrm{dak}$} & 0,075 \\
\hline 2 & & & & 0,15 \\
\hline 3 & & & & 0,225 \\
\hline 4 & & & & 0,3 \\
\hline 5 & & & \multirow{4}{*}{$50 \mathrm{~m} / \mathrm{dak}$} & 0,075 \\
\hline 6 & & & & 0,15 \\
\hline 7 & & & & 0,225 \\
\hline 8 & & & & 0,3 \\
\hline 9 & & \multirow{8}{*}{$6 \mathrm{~mm}$} & \multirow{4}{*}{$20 \mathrm{~m} / \mathrm{dak}$} & 0,075 \\
\hline 10 & & & & 0,15 \\
\hline 11 & & & & 0,225 \\
\hline 12 & & & & 0,3 \\
\hline 13 & & & \multirow{4}{*}{$50 \mathrm{~m} / \mathrm{dak}$} & 0,075 \\
\hline 14 & & & & 0,15 \\
\hline 15 & & & & 0,225 \\
\hline 16 & & & & 0,3 \\
\hline 17 & \multirow{16}{*}{ 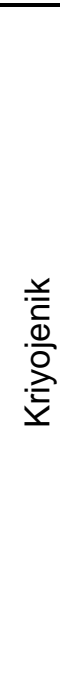 } & \multirow{8}{*}{$4 \mathrm{~mm}$} & \multirow{4}{*}{$20 \mathrm{~m} / \mathrm{dak}$} & 0,075 \\
\hline 18 & & & & 0,15 \\
\hline 19 & & & & 0,225 \\
\hline 20 & & & & 0,3 \\
\hline 21 & & & \multirow{4}{*}{$50 \mathrm{~m} / \mathrm{dak}$} & 0,075 \\
\hline 22 & & & & 0,15 \\
\hline 23 & & & & 0,225 \\
\hline 24 & & & & 0,3 \\
\hline 25 & & \multirow{8}{*}{$6 \mathrm{~mm}$} & \multirow{4}{*}{$20 \mathrm{~m} / \mathrm{dak}$} & 0,075 \\
\hline 26 & & & & 0,15 \\
\hline 27 & & & & 0,225 \\
\hline 28 & & & & 0,3 \\
\hline 29 & & & \multirow{4}{*}{$50 \mathrm{~m} / \mathrm{dak}$} & 0,075 \\
\hline 30 & & & & 0,15 \\
\hline 31 & & & & 0,225 \\
\hline 32 & & & & 0,3 \\
\hline
\end{tabular}




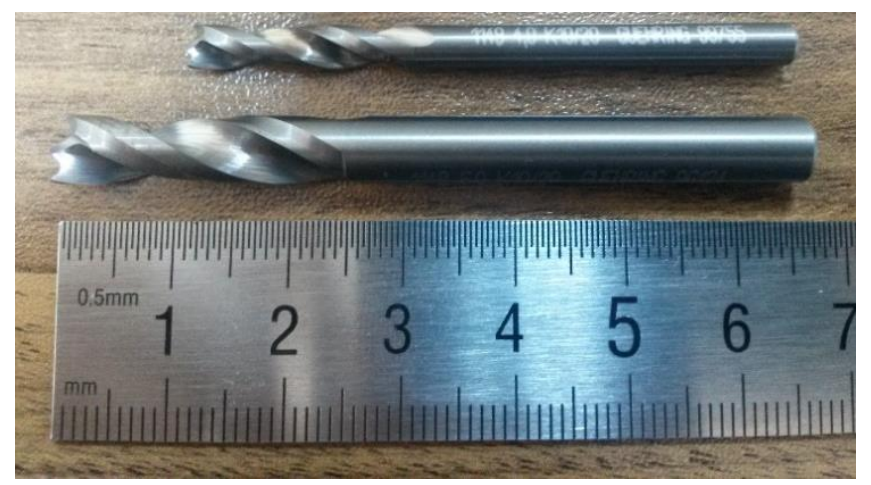

Şekil 3. Deneylerde kullanılan farklı çaplı matkaplar (4 ve $6 \mathrm{~mm}$ )

Karbon fiber takviyeli polimer kompozit malzemeler özellikle uzay, havacılık, otomotiv, spor ürünleri ve denizcilik sektöründe yaygın bir şekilde kullanılmaktadır. Bu yapılar her ne kadar final şekle yakın üretilseler bile hala son işlem olarak talaşlı imalat yöntemlerine intiyaç duyulmaktadır. Bu bağlamda bu tez çalışmasında karbon fiber takviyeli kompozit malzeme $480 \times 480 \times 5 \mathrm{~mm}$ boyutlarında temin edilmiştir. Bu kompozit malzemenin bağlama kalıbına bağlanabilmesi için $200 \times 150 \mathrm{~mm}$ boyutlarında kesilerek deneye hazır hale Şekil 4 'deki gibi getirilmiştir. Karbon fiber takviyeli kompozit malzemenin mekanik özellikleri temin edildiği firma tarafından elde edilerek Tablo 2' de belirtilmiştir.

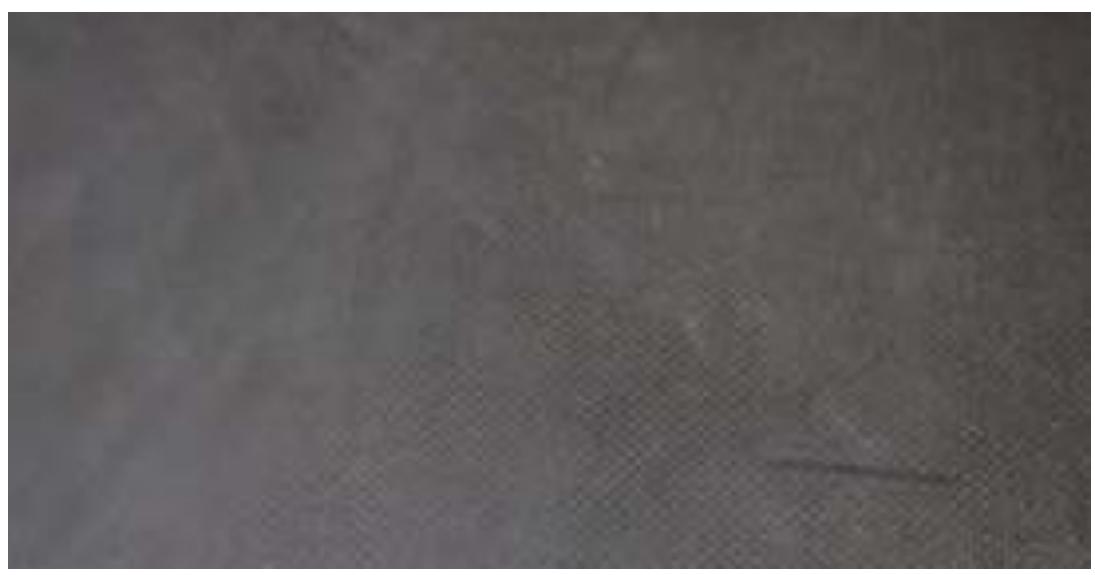

Şekil 4. Deneyde kullanılan kompozit malzeme $(200 \times 150 \mathrm{~mm})$

Tablo 2. Karbon fiber takviyeli kompozit malzemenin mekanik özellikleri

\begin{tabular}{|l|c|c|}
\hline Elyaf tipi & Karbon elyaf & $\begin{array}{c}\text { Birim veya bu- } \\
\text { lunma yüzdesi }\end{array}$ \\
\hline Reçine tipi & Epoksi & - \\
\hline Ağırlıça Elyaf İçeriği & $>60$ & $\%$ \\
\hline Hacimce Elyaf İçeriği & $>50$ & $\%$ \\
\hline Yoğunluk & $>1.5$ & $\mathrm{~g} / \mathrm{cm}^{3}$ \\
\hline Çekme mukavemeti (elyaf yönünde) & 775 & $\mathrm{Mpa}$ \\
\hline Basma mukavemeti (elyaf yönünde) & 475 & $\mathrm{Mpa}$ \\
\hline Çekme modülü (elyaf yönünde) & 63 & $\mathrm{Gpa}$ \\
\hline Bükülme mukavemeti (elyaf yönünde) & 725 & $\mathrm{Mpa}$ \\
\hline Bükülme modülü (elyaf yönünde) & 60 & $\mathrm{Gpa}$ \\
\hline
\end{tabular}


Ölçümlerin yapılması itme kuvveti matkap ilerleme yönüne zıt yönde oluşan ve matkap uç bölgesinde aşınmalara neden olabilen bu kuvvetin, delme prosesinde irdelenmesi bilimsel tamamlayıcılığı açısından önemlidir (Capello, 2004). Bu bağlamda bu çalışmada kesme anında on-line olarak itme kuvveti ölçülmüştür. Matkap ile delme anında oluşan sadece $Z$ yönündeki itme kuvveti dikkate alınmıştır.
Delaminasyon faktörü, deformasyon bölgesindeki en büyük çapın matkap çapına oranı şeklinde ve aşağıdaki formül yardımıyla hesaplanmıştır (Dokur, 2009). Deformasyon ölçümleri optik bir mikroskop (Olympus SZX7 stereo trinocular mikroskop ile $12.5 \mathrm{X}$ büyütme) kullanılarak Şekil 5 'te görüldüğü gibi yapılmıştır.

$$
d=D_{\text {maks }} / D_{\text {delik }}
$$

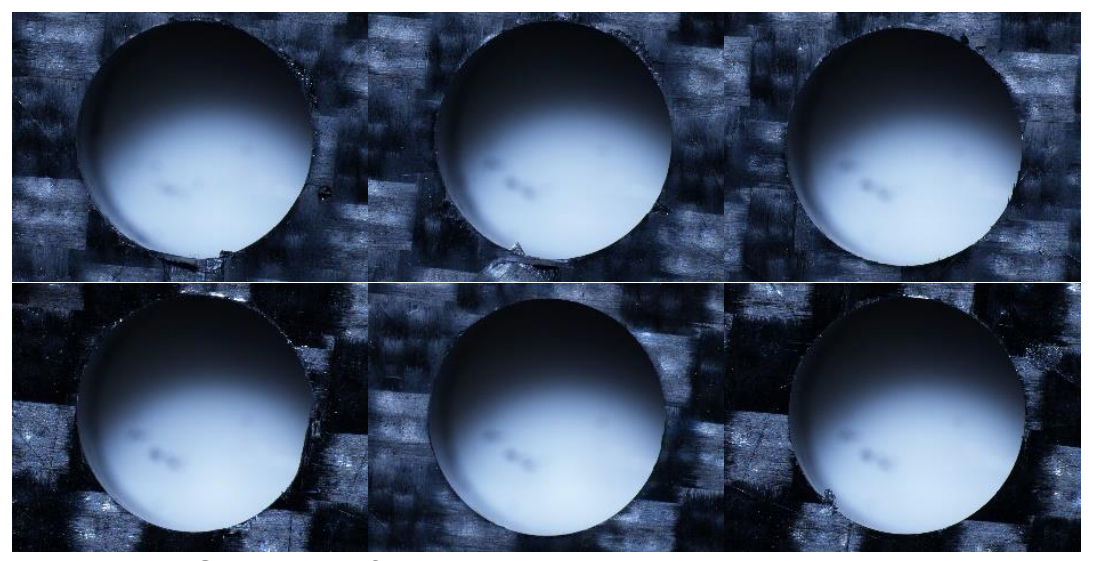

Şekil 5. Deformasyon ölçümlerinin görüntüleri

\section{BULGULAR VE TARTIŞMA}

Karbon fiber takviyeli polimer kompozit malzemenin kuru ve kriyojenik şartlar altında farklı kesme parametreleri ve farklı çaplı matkaplarla delinmesi deneysel olarak araştırılmıştır. Bu çalışmada deneylerin yapımı anında itme kuvveti, deneyden sonra ise delaminasyon faktörü ve delik çapı incelemesi yapılmıştır.

\section{İtme Kuvveti Ölçüm Sonuçları}

Matkap ile delik delme anında en fazla kuvvet matkabın ilerleme yönünde oluştuğundan diğer yönlerde oluşan kuvvetler inmal edilerek sadece $Z$ yönündeki itme kuvveti dikkate alınır. Bu çalışmada sadece itme kuvveti dikkate alınmıştır. Verilen kesme hızı ve ilerleme miktarına karşılık oluşan itme kuvveti Tablo 3'de gösterilmiştir. 
Tablo 3. Kesme Değerlerine karşılık oluşan itme kuvvetleri

\begin{tabular}{|c|c|c|c|c|c|}
\hline $\begin{array}{l}\text { Deney } \\
\text { Sayısı }\end{array}$ & & Çap (Ø) & $\begin{array}{c}\text { Kesme } \\
\text { Hızı } \\
\text { (m/dak) }\end{array}$ & $\begin{array}{c}\text { İerleme } \\
\text { Miktarı } \\
\text { (mm/dev) }\end{array}$ & $\begin{array}{c}\text { İtme } \\
\text { Kuvveti } \\
(\mathrm{N})\end{array}$ \\
\hline 1 & \multirow{16}{*}{$\begin{array}{l}\underline{D} \\
\underline{2}\end{array}$} & \multirow{8}{*}{$4 \mathrm{~mm}$} & \multirow{4}{*}{$20 \mathrm{~m} / \mathrm{dak}$} & 0,075 & 50,2 \\
\hline 2 & & & & 0,15 & 65,07 \\
\hline 3 & & & & 0,225 & 74,22 \\
\hline 4 & & & & 0,3 & 89,17 \\
\hline 5 & & & \multirow{4}{*}{$50 \mathrm{~m} / \mathrm{dak}$} & 0,075 & 39,83 \\
\hline 6 & & & & 0,15 & 54,02 \\
\hline 7 & & & & 0,225 & 66,11 \\
\hline 8 & & & & 0,3 & 66,11 \\
\hline 9 & & \multirow{8}{*}{$6 \mathrm{~mm}$} & \multirow{4}{*}{$20 \mathrm{~m} / \mathrm{dak}$} & 0,075 & 52,67 \\
\hline 10 & & & & 0,15 & 73,58 \\
\hline 11 & & & & 0,225 & 98,19 \\
\hline 12 & & & & 0,3 & 119,4 \\
\hline 13 & & & \multirow{4}{*}{$50 \mathrm{~m} / \mathrm{dak}$} & 0,075 & 42,57 \\
\hline 14 & & & & 0,15 & 87,7 \\
\hline 15 & & & & 0,225 & 121 \\
\hline 16 & & & & 0,3 & 152,3 \\
\hline 17 & \multirow{16}{*}{ 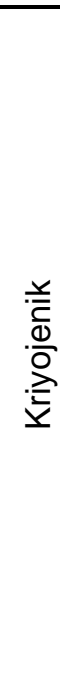 } & \multirow{8}{*}{$4 \mathrm{~mm}$} & \multirow{4}{*}{$20 \mathrm{~m} / \mathrm{dak}$} & 0,075 & 77,39 \\
\hline 18 & & & & 0,15 & 112,9 \\
\hline 19 & & & & 0,225 & 138,2 \\
\hline 20 & & & & 0,3 & 184,4 \\
\hline 21 & & & \multirow{4}{*}{$50 \mathrm{~m} / \mathrm{dak}$} & 0,075 & 55,4 \\
\hline 22 & & & & 0,15 & 85,97 \\
\hline 23 & & & & 0,225 & 109 \\
\hline 24 & & & & 0,3 & 134,8 \\
\hline 25 & & \multirow{8}{*}{$6 \mathrm{~mm}$} & \multirow{4}{*}{$20 \mathrm{~m} / \mathrm{dak}$} & 0,075 & 80,48 \\
\hline 26 & & & & 0,15 & 186,4 \\
\hline 27 & & & & 0,225 & 221,9 \\
\hline 28 & & & & 0,3 & 257,1 \\
\hline 29 & & & \multirow{4}{*}{$50 \mathrm{~m} / \mathrm{dak}$} & 0,075 & 146,2 \\
\hline 30 & & & & 0,15 & 207,1 \\
\hline 31 & & & & 0,225 & 269,4 \\
\hline 32 & & & & 0,3 & 339,9 \\
\hline
\end{tabular}

Kuru kesme şartları ile yapılan deney sonunda elde edilen itme kuvveti grafiği Şekil 6'da verilmiştir. Şekil 6'da görüldüğü üzere $4 \mathrm{~mm}$ çaplı matkaplar daha düşük itme kuvveti oluşturmaktadır. Küçük çaplı matkapta kesme hızının artması itme kuvvetini düşürürken çap artması ile tam tersi bir durum ortaya çıkmıştır. Ayrıca ilerleme miktarının artması ile itme kuvveti artmaktadır.

Kriyojenik şartları ile yapılan deney sonunda elde edilen itme kuvveti grafiği Şekil 6'da verilmiştir. Grafiklerden de görüldüğü üzere $4 \mathrm{~mm}$ çaplı matkaplar daha düşük itme kuvveti oluşturmaktadır. Küçük çaplı matkapta kesme hızının artması itme kuvvetini düşürürken çap artması ile tam tersi bir durum ortaya çıkmıştır. Ayrıca ilerleme miktarının artması ile itme kuvveti artmaktadır. Son olarak kriyojenik şartlarda oluşan itme kuvvetleri kuru kesme şartlarında yaklaşık 2 kat daha fazladır. 


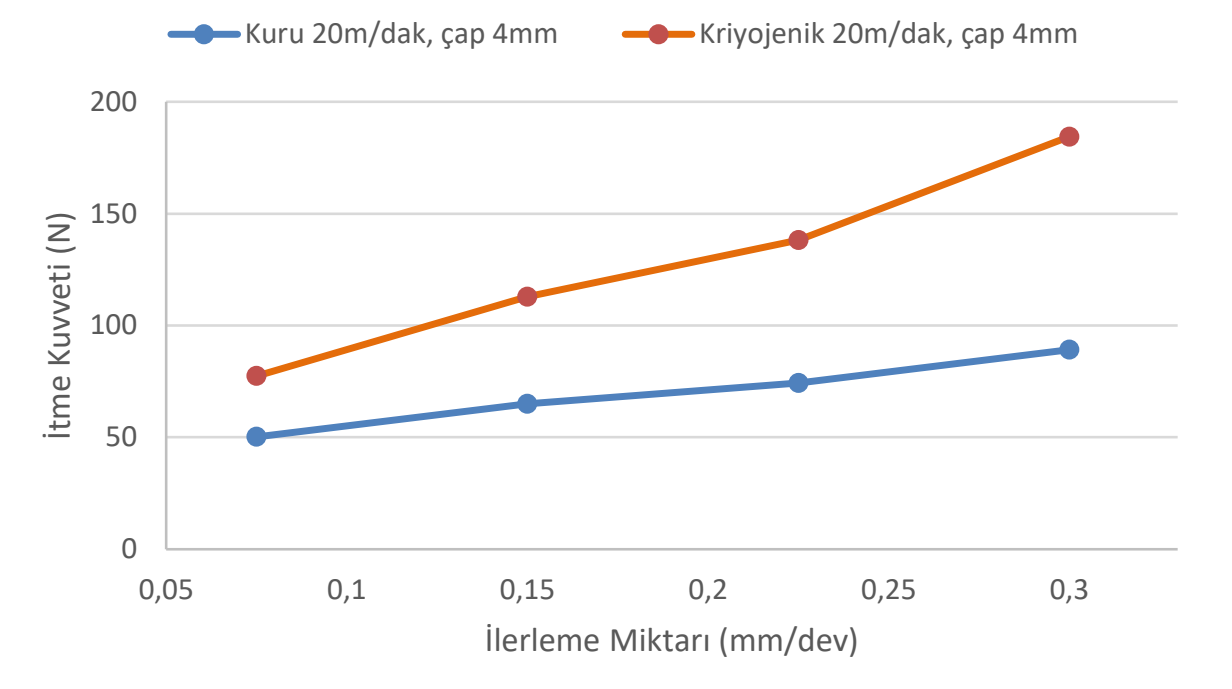

Şekil 6. Kuru ve Kriyojenik Kesme Şartlarında Farkı Kesme Şartlarının İtme Kuvvetine etkisi

Karbon fiber takviyeli kompozit malzemeye $50 \mathrm{~m} /$ dak. kesme hızı ile, $0.15 \mathrm{~mm} / \mathrm{dev}$. ilerleme miktarı ile $6 \mathrm{~mm}$ çaplı matkapla 324 delik açılmıştır. Deneyler hem kuru hem de kriyojenik şartlar ile yapılmıştır. Delik sayısının artması ile itme kuvvetleri her iki kesme şartlarında da artmıştır. Ayrıca kriyojenik şartlarda daha fazla kuvvet oluşmaktadır

\section{Delaminasyon Ölçüm Sonuçları}

Karbon fiber takviyeli kompozit malzemenin delinmesi anında malzemede birçok hasar oluşmaktadır. Bunlardan en önemlisi delaminasyon hasarıdır. Delaminasyon faktör diye adlandırılır ve maksimum hasarlı çapın nominal çapa bölünmesi ile elde edilir. Şekil 7'de kesme parametreleri ve matkap çapının delaminasyon faktöre etkisi verilmiştir. Şekilden de görüldüğü gibi ilerleme oranının artması ile delaminasyon hasarı artmaktadır. Büyük çaplı matkap daha fazla delaminasyon hasar oluşturmaktadır. $4 \mathrm{~mm}$ çaplı matkap ile $50 \mathrm{~m} /$ dak kesme şartlarına en az delaminasyon hasar oluşurken, $6 \mathrm{~mm}$ çaplı matkap ile $50 \mathrm{~m} /$ dak kesme hızında yapılan deneyden ise en fazla delaminasyon oluşmaktadır.

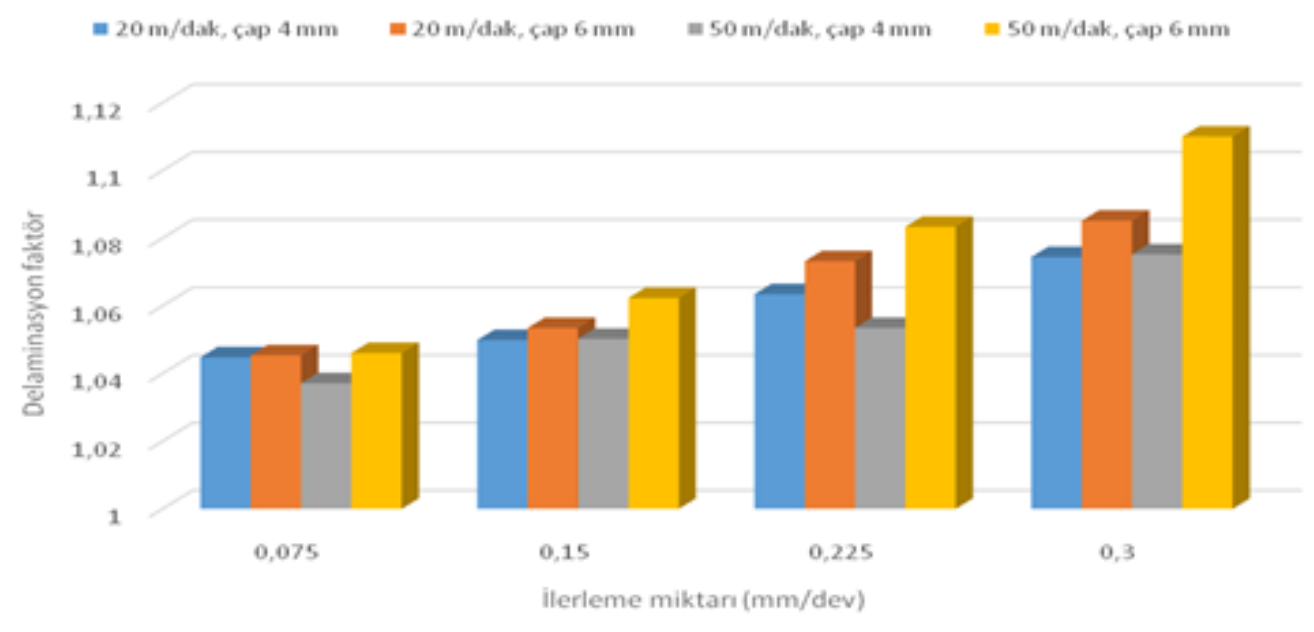

Şekil 7. Kuru Kesme Şartlarında Farklı Kesme Şartlarının Delaminasyon Hasarına Etkisi

Kriyojenik şartlar ile karbon fiber takviyeli kompozit malzemenin delinmesinde farklı çapların, kesme hızı ve ilerleme oranlarının delaminasyon hasarına etkisi Şekil 8'de verilmiştir. Büyük çaplı matkap daha fazla delaminasyon hasar oluşturmaktadır. En az delaminasyon hasar 20 
$\mathrm{m} /$ dak. kesme hızında $4 \mathrm{~mm}$ çaplı matkapla elde edilirken, en fazla delaminasyon ise $20 \mathrm{~m} /$ dak. kesme hızında $6 \mathrm{~mm}$ çaplı matkap ile elde edilmiştir. Kriyojenik şartlar ile kuru kesmeye nazaran daha fazla delaminasyon hasarı elde edilmiştir.

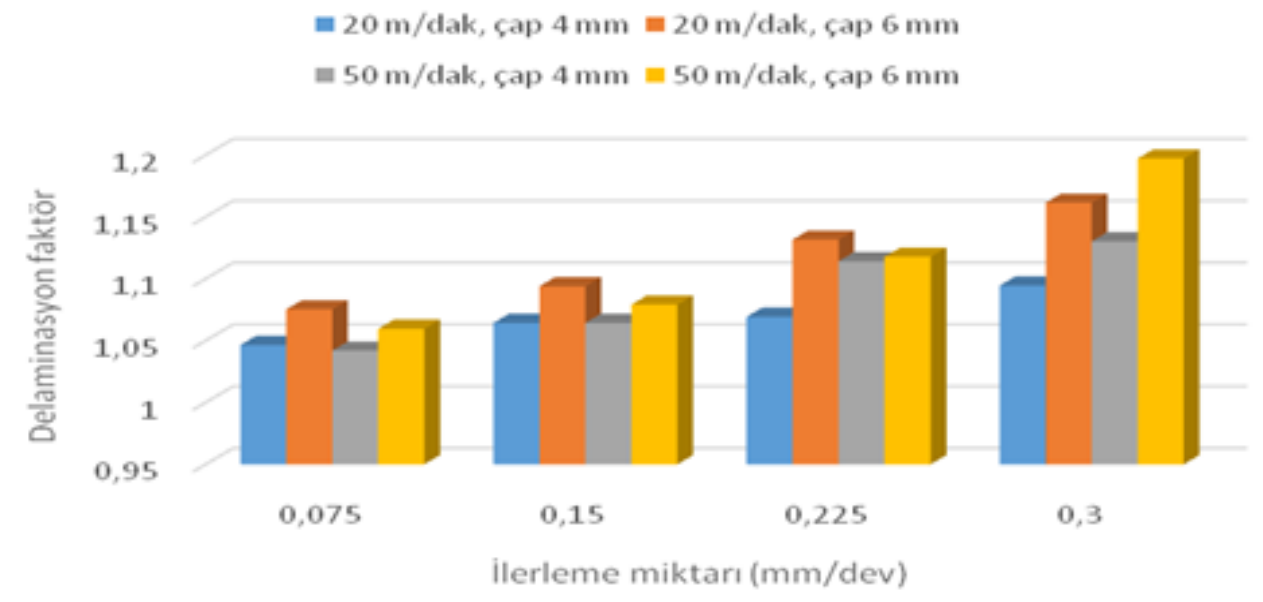

Şekil 8. Kriyojenik kesme şartlarında farklı kesme şartlarının delaminasyon hasarına etkisi

Karbon fiber takviyeli kompozit malzemeye $50 \mathrm{~m} /$ dak. kesme hızı ile, $0.15 \mathrm{~mm} / \mathrm{dev}$. ilerleme miktarı ile $6 \mathrm{~mm}$ çaplı matkapla 324 delik açılmıştır. Deneyler hem kuru hem de kriyojenik şartlar ile yapılmıştır. Delik sayısının artması ile delaminasyon hasarı artmaktadır. Ayrıca kriyojenik şartlarda daha fazla hasar oluşmaktadır.

\section{Koordinat ÖIçüm Cihazı (CMM) Ölçüm Sonuçları}

Kuru kesme şartlarında yapılan deney neticesinde elde edilen delikler CMM cihazında Şekil 9'da ölçülmüş olup elde edilen değerler grafiklere Şekil 10'da ve Şekil 11'de olduğu gibi dönüştürülmüştür. Matkap çapları 4 ve 6 mm'dir. $4 \mathrm{~mm}$ çaplı matkap ile yapılan delme testlerinde $50 \mathrm{~m} /$ dak. kesme hızı ile yapılan deneyin istenen çapa daha yakın çıktığı grafikten görülmektedir. $6 \mathrm{~mm}$ çaplı matkap kullanılmasıyla yapılan deneyde ise $20 \mathrm{~m} /$ dak. kesme hızının daha iyi netice verdiği söylenebilir.
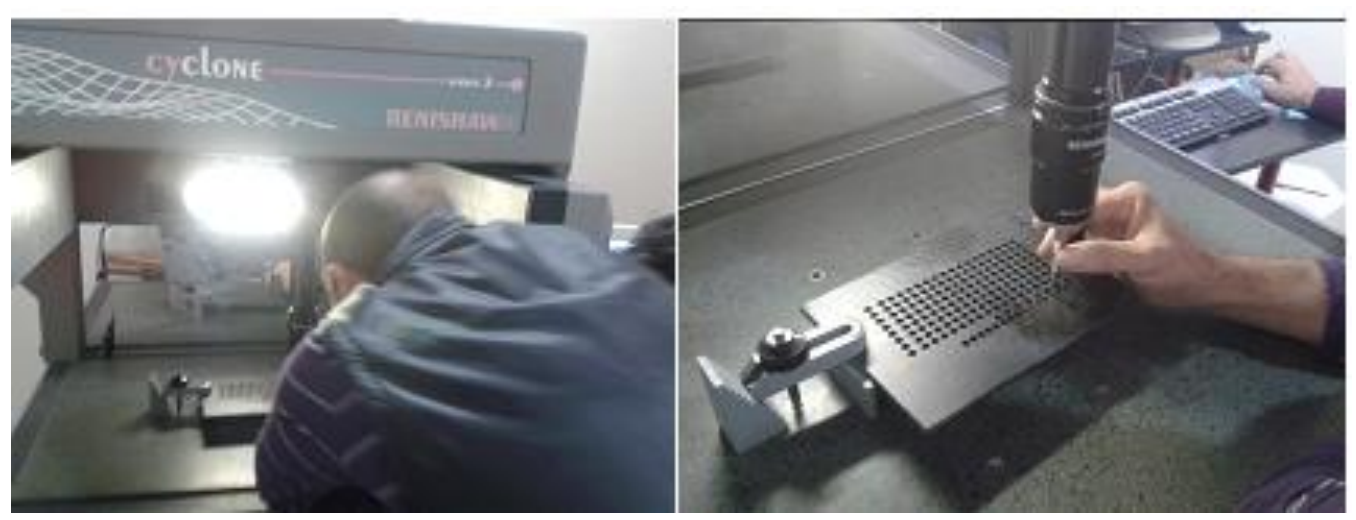

Şekil 9. CMM cihazında delik ölçümü 

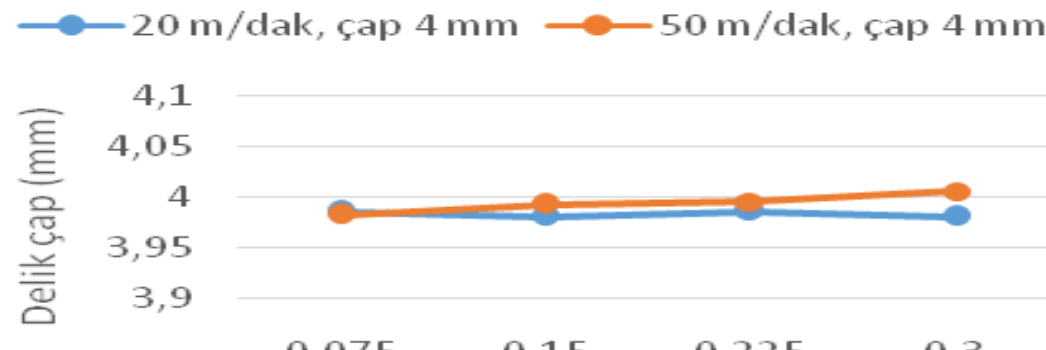

4,1

4

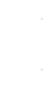

3,9
0.075
0.15
0.225
0.3
ilerleme miktarı ( $\mathrm{mm} / \mathrm{dev})$

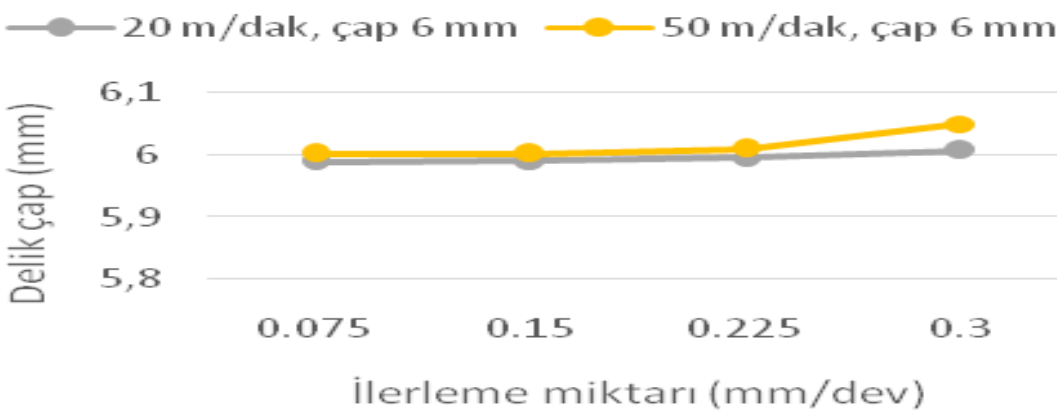

Şekil 10. Kuru kesme şartlarında kesme parametrelerinin delik çapına etkisi

$4 \mathrm{~mm}$ çaplı matkap kullanarak $50 \mathrm{~m} /$ dak. kesme hızı ile yapılan deneyde dalgalı bir çap değişimi izlenirken, 20 $\mathrm{m} /$ dak. kesme hızında daha stabil bir eğri elde edilmiştir. İstenen çaptan sapmalar burada da meydana gelmiştir. $6 \mathrm{~mm}$ çaplı matkap ile yapılan deneyden elde edilen çap değerleri incelendiğinde $20 \mathrm{~m} /$ dak. kesme hızının daha iyi neticeler verdiği söylenebilir. Çap $6 \mathrm{~mm}$ kriyojenik şartlar da elde edilen delikler kuru kesmeye nazaran daha iyi olduğu aşikârdır. Çap $4 \mathrm{~mm}$ ise kuru şartlarda daha iyi sonuçlar elde edilmiştir.

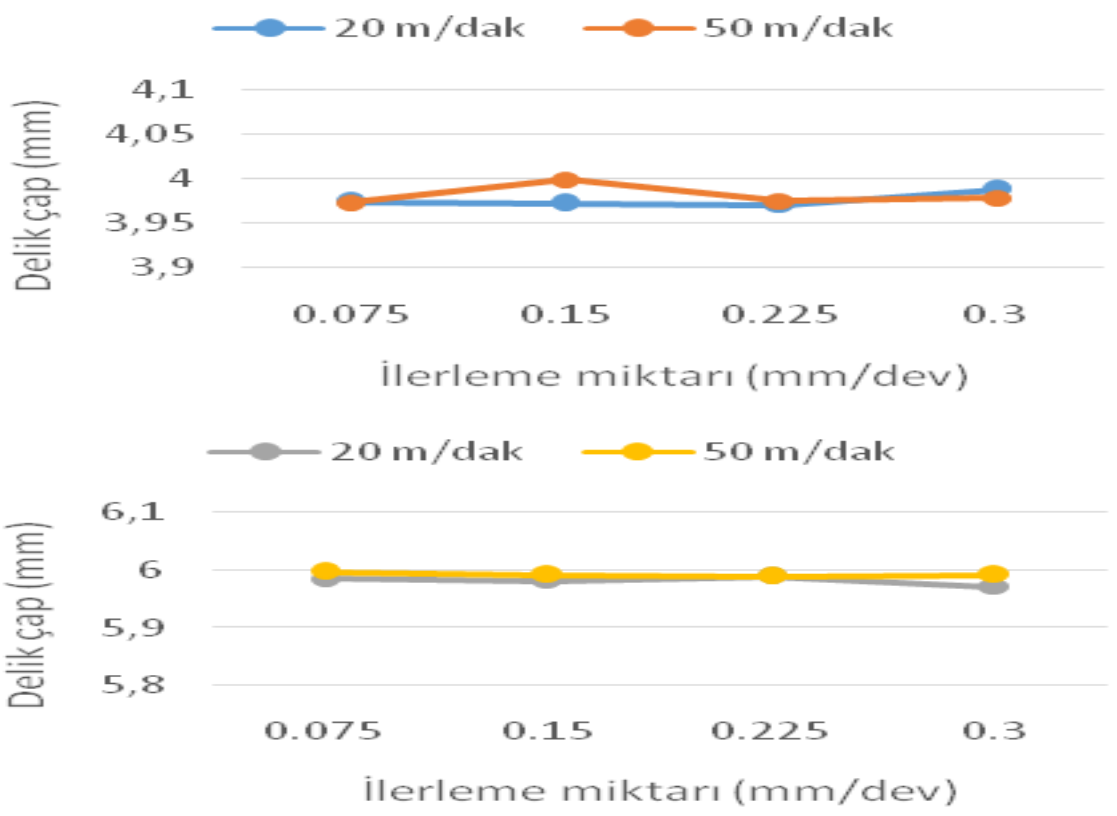

Şekil 11. Kriyojenik kesme şartlarında kesme parametrelerinin delik çapına etkisi 
Karbon fiber takviyeli kompozit malzemeye $50 \mathrm{~m} / \mathrm{dak}$. kesme hızı ile, $0.15 \mathrm{~mm} / \mathrm{dev}$. ilerleme miktarı ile $6 \mathrm{~mm}$ çaplı matkapla 324 delik açılmıştır. Deneyler hem kuru hem de kriyojenik şartlar ile yapıımıştır. Kuru ve kriyoje- nik şartlarda elde edilen deliklerin ölçüleri Şekil 12'de görüldüğü gibi $6 \mathrm{~mm}$ den daha az çıkmıştır. Kriyojenik şartlarda daha dalgalı ölçümler elde edilirken, kuru kesme da daha stabil çap değerleri elde edilmiştir.

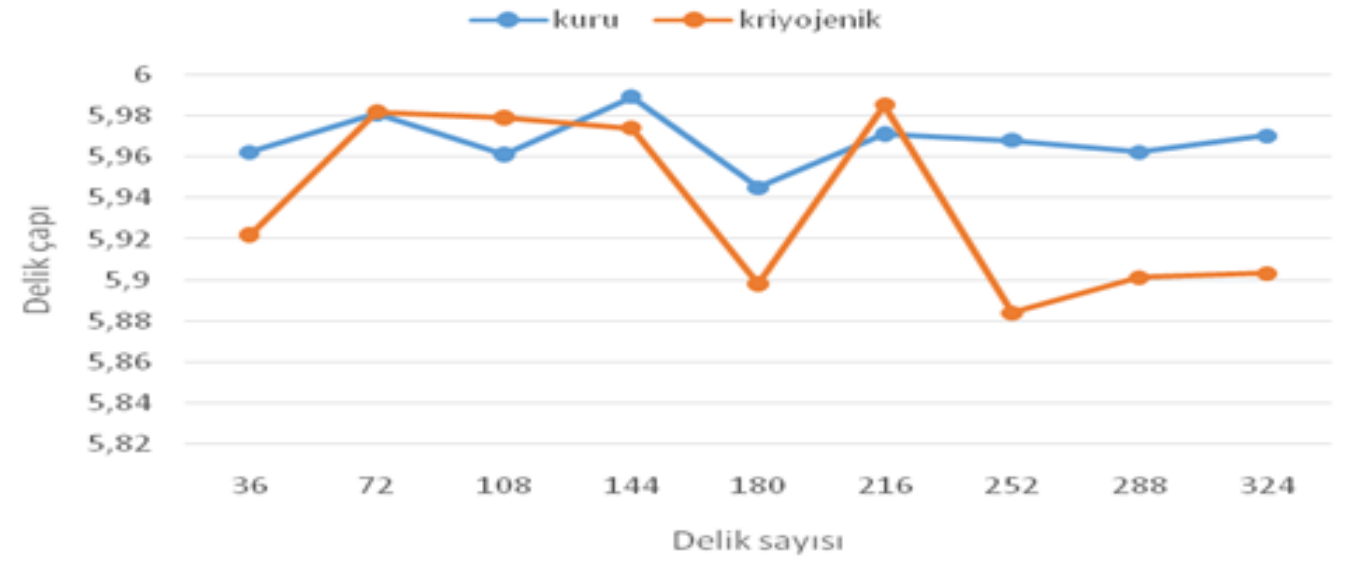

Şekil 12. Delik sayısı artışı ile delik çap değişimi

\section{SONUÇLAR}

Bu çalışmada karbon fiber takviyeli polimerik kompozit malzemenin kuru ve kriyojenik şartlar altında farklı kesme parametreleri kullanarak delinebilirlik performansı deneysel olarak araştırılmıştır. Deneysel çalışmada iki farklı kesme hızı (20 ve $50 \mathrm{~m} /$ dak.), dört farklı ilerleme miktarı $(0.075 \mathrm{~mm} / \mathrm{dev}$., $\quad 0.15 \mathrm{~mm} / \mathrm{dev}$., $0.225 \mathrm{~mm} / \mathrm{dev}$. ve $0.3 \mathrm{~mm} / \mathrm{dev}$ ) ve 2 farklı çaplı matkaplar (4 mm ve $6 \mathrm{~mm}$ ) kullanılmıştır. Deneysel çalışma anında on-line olarak itme kuvvetleri, deneylerden sonra ise delaminasyon hasarı görüntülenmiştir.

Karbon fiber takviyeli polimerik kompozit malzemenin delinmesinde kriyojenik şartlarda oluşan kuvvet kuru kesme şartlarında oluşan kuvvetin yaklaşık 2 kat daha fazla çıkmıştır.

Kriyojenik şartlar altında daha fazla kuvvet oluşmasının nedeni ise malzemenin aşırı soğuğa maruz kalmasıyla malzemenin young modülünü, çekme gerilmesini artırmasıdır. Çekme gerilmesinin artması ile malzeme sert ve kırılgan bir yapıya dönüştüğünden talaş kaldırma operasyonu zorlaşmaktadır.

Daldırma kriyojenik tekniği ile CFRP'nin delinmesinin kolaylaştığı, delinmiş parçaların yüzey pürüzlülüğünü azaltarak işlenebilirliği büyük ölçüde artırdığını göstermiştir.

Delaminasyon oluşumu ile oluşan kuvvet arasında doğrudan bir ilişki vardır. Bu bağlamda kriyojenik şartlarda kuru kesme şartlarına göre daha fazla delaminasyon oluşmaktadır.
Deneysel çalışmadan elde edilen sonuçlara göre $4 \mathrm{~mm}$ çaplı matkap $6 \mathrm{~mm}$ çaplı matkap dan daha iyi sonuçlar verdiği görülmüştür. Tasarım olarak izin verilen tüm durumlarda küçük çaplı matkaplar tercih edilmesi daha iyi sonuçlar vereceği görülmüştür.

\section{KAYNAKLAR}

Ananda, R.S., Patra, K. (2017). Mechanistic cutting force modelling for micro-drilling of CFRP composite laminates. CIRP Journal of Manufacturing Science and Technology, 16: 55-58.

Brinksmeier, E., Fangmann, S., Rentsch, R. (2011). Drilling of Composites and Resulting Surface Integrity, CIRP AnnalsManufacturing Technology. 60: 57-60.

Capello, E. (2004). Workpiece Damping and İts Effect on Delamination Damage in Drilling Thin Composite Laminates. Journal of Materials Processing Technology. 148:186195.

Dokur, M. M. (2009). Karbon Fiber Esaslı Polimerik Matrisli Kompozitlerin Üretimi ve Karakterizasyonu. ITÜ Fen Bilimleri Enstitüsü Yüksek Lisans Tezi.

Ekici, E., Işık, B. (2009). Cam Elyaf Takviyeli Polimer Kompozit Malzemenin Delinmesi Esnasında Oluşan Yüzey Hasarının Deneysel Olarak İncelenmesi 5. Uluslararası Illeri Teknolojiler Sempozyumu, 13-15 Mayıs, Karabük, Türkiye, Book of Proceedings, 20-26p.

Gaitonde, N., Karnik, S.R., Rubio Campos J., Correia Esteves A., AbraoAM., Paulo Davim J. (2008). Analysis of Parametric İnfluence on Delamination in High-Speed Drilling of Carbon Fiber Reinforced Plastic Composites. Journal of Materials Processing Technology. 203: 431-438.

Geng, D., Liu, Y., Shao, Z., Lui, Z., Cai, J., Li, X., Jiang, X., Zhang, D. (2019). Delamination formation, evaluation and suppression during drilling of composite laminates: A review. Composite Structures 
216: 168-186.

Liyakhath, A.S., Kumar, M. P. (2015). Cryogenic drilling of Ti6Al-4V Alloy Under Liquid Nitrogen Cooling. Materials and Manufacturing Processes, 31: 951-959.

Meral, G., Dilipak, H., Sarıkaya, M. (2011). AISI 1050 Malzemenin Delinmesinde İlerleme Kuvvetleri Ve Yüzey Pürüzlülüğünün Regresyon Metoduyla Modellenmesi. TÜBAV Bilim Dergisi, 4(1): 31-41.

Palanikumar, K., Srinivasan, T., Rajagopal, K., Latha, B. (2016). Thrust Force Analysis in Drilling Glass Fiber Reinforced/Polypropylene (gfr/pp) Composites. Materials and Manufacturing Processes, 31: 581-586.
Seeholzer, L., Scheuner, D., Wegener, K. (2019). Analytical force model for drilling out unidirectional carbon fibre reinforced polymers (CFRP). Journal of Materials Processing Technology. 1: 116-489.

Shunmugesh, K., Panneerselvam, K. (2016). Machinability Study of Carbon Fiber Reinforced Polymer in the Longitudinal and Transverse Direction and Optimization of Process Parameters Using PSO-GSA. Eng. Sci. Technol. Int. J. 19 1552-1563.

Wang, F., Wang, X., Zhao, X., Bi, G., Fu, R. (2020). A numerical approach to analyze the burrs generated in the drilling of carbon fiber reinforced polymers (CFRPs). The International Journal of Advanced Manufacturing Technology. 106:3533-3546. 